\title{
Evaluation of the applicability of deep breathing test in the diagnosis of hypertension with white-coat effect in Chinese patients in primary care
}

Kam Sum Chan ${ }^{*}$ (D) Kit Ping Loretta Lai, Pang Fai Chan, Man Hei Matthew Luk and Vai Kiong David Chao

\begin{abstract}
Purpose: The current gold standard for the diagnosis of white-coat effect is by the 24-h ambulatory blood pressure monitoring (ABPM) which may not be readily available in every primary care setting. Previous studies had shown that deep breathing, through modulating the baroreceptor reflex sensitivity to vagal stimulation over 30 to $60 \mathrm{~s}$, was useful in detection of the white-coat effect. The aim of our study was to evaluate the diagnostic accuracy of the deep breathing test (DBT) as compared with the gold standard of ABPM in the diagnosis of hypertension with white-coat effect in Chinese patients in primary care.
\end{abstract}

Methods: This cross sectional study recruited 178 consecutive, eligible, consented, hypertensive patients receiving treatment at a local public primary care Hypertension Clinic.

The diagnostic accuracy of the DBT in all recruited patients, patients not taking beta-adrenergic blockers and patients with different clinic SBP cut-off before the DBT by means of area under the receiver operating characteristic (ROC) curve, sensitivity, specificity, positive and negative predictive values was evaluated.

Results: The results for the ROC curves for systolic and diastolic BP changes after the DBT were statistically insignificant. The ROC curve was statistically significant for SBP change in patients not taking beta-adrenergic blockers and with pre-DBT clinic SBP $\geq 165 \mathrm{mmHg}$ (ROC curve area of $0.719,95 \% \mathrm{Cl} 0.53$ to $0.91, p=0.04$ ). The corresponding sensitivity and specificity of the DBT were 40.9 and $90.9 \%$ respectively if SBP drop was $>30 \mathrm{mmHg}$.

Conclusion: The DBT, even though could not be clinically applied to all patients, was proven to be a potential screening and diagnostic test for white-coat effect in Chinese hypertensive patients with a pre-test SBP of $\geq 165$ $\mathrm{mmHg}$ and who were not taking beta-adrenergic blockers.

Trial registration: This study was approved by Kowloon East Cluster/ Kowloon Central Cluster Research Ethics Committee/Institutional Review Board of Hospital Authority of Hong Kong under the registration KC/KE-16-0084/ER-3.

Keywords: White-coat effect, Deep breathing test, Hypertension, Primary care

\footnotetext{
* Correspondence: chankamsum@hotmail.com

Department of Family Medicine and Primary Health Care, United Christian

Hospital and Tseung Kwan O Hospital, Kowloon East Cluster, Hospital

Authority, Tseung Kwan O, Hong Kong, China
}

(c) The Author(s). 2019 Open Access This article is distributed under the terms of the Creative Commons Attribution 4.0 International License (http://creativecommons.org/licenses/by/4.0/), which permits unrestricted use, distribution, and reproduction in any medium, provided you give appropriate credit to the original author(s) and the source, provide a link to the Creative Commons license, and indicate if changes were made. The Creative Commons Public Domain Dedication waiver (http://creativecommons.org/publicdomain/zero/1.0/) applies to the data made available in this article, unless otherwise stated. 


\section{Introduction}

Hypertension, being a major constituent to the global burden of non-communicable diseases [1], was reported to be prevalent in around 32\% of the Hong Kong population in a local large cohort study in 2012 [2]. It is a leading risk factor of cardiovascular diseases which cause significant morbidity and mortality [3, 4]. However, only about half of the treated hypertensive patients achieved target blood pressures according to international studies [5, 6]. The reasons accounting for suboptimal blood pressure control included inadequate treatment, poor patient adherence, white-coat hypertension, undiagnosed secondary hypertension and true resistant hypertension [7, 8].

White-coat hypertension is defined as persistently raised office blood pressure in ambulatory normotensive patients [9]. It accounts for up to 20 to $30 \%$ of patients worldwide [10-12]. White-coat effect refers to a patient with home or ambulatory blood pressure within the hypertensive range but who exhibit a disproportionately raised clinic blood pressure reading [9]. It was reported to account for one in four of the treated hypertensive patients with suboptimal office blood pressure control $[13,14]$ and prevalent among $35-73 \%$ of patients with treated hypertension [12, 15-19]. Factors associated with white-coat hypertension including female sex, white ethnicity, increasing age, higher body mass index, higher clinic systolic blood pressure and declining renal function $[12,20,21]$.

The detection of white-coat effect is important as failure to recognise the condition may lead to unnecessary treatment causing undesirable side effects for the patients and also inflating the cost of treatment [22-24]. Current gold standard for the diagnosis of white-coat effect is by the 24-h ambulatory blood pressure monitoring (ABPM) which can provide information about blood pressure during daily activities and sleep and thus better evaluation of white-coat effect than home blood pressure $[9,25,26]$. However, ABPM requires specific equipment and expertise to operate and may not be available in every primary care setting.

Deep breathing was shown to be able to lower blood pressure by increasing the baroreceptor reflex sensitivity to vagal stimulation $[27,28]$. Studies had shown that deep breathing over 30 to $60 \mathrm{~s}$ was useful in detection of the white-coat effect by measuring the difference in systolic blood pressure (SBP) after performing the deep-breathing test (DBT) [29-32]. In the Federico et al. study, the DBT resulted in a statistically significant difference in mean SBP drop of 17.8 and $10.9 \mathrm{mmHg}(p<0.001)$ among patients with or without white-coat effect respectively [29]. In the Marion et al. study, a 15\% drop in SBP was found to be corresponded to a $96 \%$ specificity (95\% CI 79.0-100.0) and $94 \%$ positive predictive value (95\% CI $72.0-100.0)$ in the diagnosis of white-coat hypertension [30]. The Jose et al. study evaluated the diagnostic accuracy of DBT on identifying white-coat hypertension. The study adopted two criteria as a positive response to DBT: a $10 \mathrm{mmHg}$ drop in diastolic blood pressure (DBP) or normalisation of SBP to $<140 \mathrm{mmHg}$ and DBP $<90 \mathrm{mmHg}$. They found no significant difference $(p<0.26)$ between the hypertensive patients with or without white-coat effect when using the first criterion but was able to identify a significant difference $(p<0.003)$ using the second criterion when applied to patients with office $\mathrm{SBP}<160 / 100 \mathrm{mmHg}$ [31]. The application of DBP drop in predicting white-coat hypertension was only found useful in the Yoshihara et al. study [32].

Previous evidence also supported a positive correlation between office SBP and white-coat effect [20, 21]. In a Taiwanese study which compared the characteristics of patients with or without white-coat effect as defined by the gold standard 24h ABPM, office SBP was found to be significantly correlated with white-coat effect (odd ratio $1.079,95 \%$ CI $1.034-1.125, p<0.001$ ) [20]. In another large scale study involving over 2000 patients in Greece, a $1.0 \mathrm{mmHg}$ increase in daytime SBP variability was correlated with an increase of $0.589 \mathrm{mmHg}$ [95\% CI $0.437-0.741$ ] in the systolic white coat effect [21].

There was also evidence showing that beta-adrenergic blockers might potentiate the baroreflex, possibly through enhancing heart-rate variability and increasing the vagal tone while reducing the sympathetic beta-receptor stimulation and therefore might affect the DBT results [33, 34]. However, the effect of beta-adrenergic blockers on DBT was not considered in all the previous mentioned studies in detecting white-coat effect. To our knowledge, all of the current evidence of clinical application of DBT was derived from non-Chinese population. There was a lack of research data on the validity of DBT in detecting white-coat effect within the Chinese hypertensive population. The effects of different clinic SBP and the use of beta-adrenergic blockers on the application of DBT in Chinese were also lacking. This study therefore aimed to evaluate the applicability of DBT as an alternative diagnostic test of white-coat effect, which would be much less time and resource consuming as compared with the 24-h ABPM in Chinese hypertensive patients. Sub-analysis on the applicability of DBT in detecting white-coat effect in patients with different clinic SBP cut-off and patients not taking beta-adrenergic blockers would also be performed.

\section{Methodology}

\section{Study design}

This was a cross sectional study conducted in a public primary care clinic serving more than 10,000 hypertensive patients in year 2015. When patient failed to reach target clinic blood pressure during consecutive follow up visits, 
they would be asked to bring their home blood pressure machine for validation along with their home blood pressure record. If there was a significant discrepancy between the clinic blood pressure and home blood pressure as measured by a validated home blood pressure machine, they would be referred to the Hypertension Clinic for further evaluation by family medicine specialists. Consecutive patients on anti-hypertensives, attending the Hypertension Clinic and fulfilled the inclusion criteria i.e. with clinic $\mathrm{SBP} \geq 140 \mathrm{mmHg}$ and/or $\mathrm{DBP} \geq 90 \mathrm{mmHg}$ at latest two clinic visits during the study period were included. Only those who aged 18 years or above and agreed to give consent in participating in the study were recruited until the required sample size was reached. Non-Chinese patients, patients with suspected secondary hypertension or atrial fibrillation and pregnant patients were excluded. The study was conducted from 1st August 2016 to 30th September 2017. This study was approved by Kowloon East Cluster/ Kowloon Central Cluster Research Ethics Committee/Institutional Review Board of Hospital Authority of Hong Kong.

\section{Procedures}

All clinic blood pressure readings were obtained in sitting position with the measuring cuff at heart level, using the calibrated manual sphygmomanometers (UM-101, A\&D instruments Ltd., Abingdon, Oxon, U.K) and appropriate cuff sizes. The patient, after resting for at least $5 \mathrm{~min}$, would have his or her blood pressure measured at both arms. The second blood pressure, spaced 2 min apart would then be taken at the arm with higher measured blood pressure [26]. The highest blood pressure values would be used as the clinic blood pressure before performing the DBT. During the DBT, the patient had to take deep breathing cycles for sixty seconds, around one cycle every ten seconds. The patient would be instructed to simulate the respiratory pattern based on an application of tempo counter installed in a smartphone. Another blood pressure would be measured immediately after the DBT on the previously chosen arm. All blood pressure measurements and DBTs would be performed by the same trained nurse blinded to the 24-h ABPM results.

Subsequently, a monitor (TM-2430, A\&D instruments Ltd., Abingdon, Oxon, U.K) would be installed to perform the 24-h ABPM with an appropriate cuff placed on the non-dominant arm and programmed to measure blood pressure every $30 \mathrm{~min}$ while patients were awaked and $60 \mathrm{~min}$ while patients were asleep. The awake and sleeping time would be programmed individually based on the history given by patients. Patients with ABPM reports showing more than 80\% successful readings would be included and their results would be interpreted by family medicine specialists who were blinded to the DBT results. There was no internationally standardized definition on the interpretation of white-coat effect by using the 24-h ABPM. In this study, it would be defined as a decrease of $10 \mathrm{mmHg}$ or more in mean daytime ambulatory SBP when compared with the clinic SBP [9].

Patients' demographic data including age, gender, body mass index, smoking status, presence of diabetes and cardiovascular diseases and number and types of anti-hypertensives taken were retrieved from computerized record.

\section{Sample size calculation}

Previous studies showed that the sensitivity of using $10 \mathrm{mmHg}$ difference as cut-off to define white-coat effect after DBT was 0.8 [29]. The prevalence of white-coat effect in hypertensive Chinese patients was lacking. Taking $35 \%$ as the most conservative estimated prevalence of white-coat effect in treated hypertensive patients in previous international studies [12, 15-19] and maximum marginal error of estimate as 0.10 , the sample size needed was 176 [35].

\section{Outcome}

The main outcome was to evaluate the diagnostic accuracy of the DBT for white-coat effect by means of area under the receiver operating characteristic (ROC) curve, sensitivity, specificity, positive and negative predictive values in Chinese hypertensive patients. Sub-analysis on the effect of beta-adrenergic blockers and different clinic SBP cut-off on the diagnostic accuracy of the DBT would also be evaluated. Blood pressure responses to DBT in all patients and different sub-groups with or without white-coat effect would be presented in terms of mean blood pressure drop after the test.

\section{Statistical analysis}

Central tendencies and distributions of continuous variables were presented as means and standard deviations respectively. The means of continuous variables were compared with independent samples $t$ test. Categorical variables were presented as proportions and percentages. They were compared with Chi-square test (with Yate's correction for $2 \times 2$ comparisons) or Fisher's exact test. Areas under the receiver operating characteristic (ROC) curve, sensitivity, specificity, positive and negative predictive values were calculated to assess the diagnostic accuracy of the DBT, with respective $95 \%$ confidence interval. Differences were considered statistically significant when $p<0.05$. SPSS version 21 was used for statistical analysis. 


\section{Results}

\section{Study population}

Five Hundred forty-eight patients attended the Hypertension Clinic during the study period and 209 patients fulfilled the inclusion criteria. 30 (14.4\%) patients refused to participate and 1 patient was excluded due to insufficient ABPM data resulting in 178 patients being recruited into the study. The mean age

Table 1 Demographic data and clinical characteristics of patients with white-coat and without white-coat effect $(N=178)$

\begin{tabular}{|c|c|c|c|c|}
\hline \multirow[t]{2}{*}{ Clinical characteristics } & \multicolumn{2}{|l|}{ White-coat effect } & \multirow{2}{*}{$\begin{array}{l}\text { Total no. } \\
(\%)\end{array}$} & \multirow[t]{2}{*}{$p$ value } \\
\hline & Present $(n=122)$ & Absent $(n=56)$ & & \\
\hline \multicolumn{5}{|l|}{ Age (years) } \\
\hline Mean & 65.6 (SD 9.7) & 63.8 (SD 10.7) & 65.0 (SD 10) & \multirow[t]{4}{*}{0.270} \\
\hline No. of patients $<40$ & 1 & 1 & $2(1.1)$ & \\
\hline $40-49$ & 8 & 4 & $12(6.7)$ & \\
\hline $50-59$ & 23 & 14 & $37(20.8)$ & \\
\hline $60-69$ & 48 & 19 & $67(37.7)$ & \multirow[t]{3}{*}{0.791} \\
\hline $70-79$ & 34 & 16 & $50(28.1)$ & \\
\hline$\geq 80$ & 8 & 2 & $10(5.6)$ & \\
\hline \multicolumn{5}{|l|}{ Sex } \\
\hline Male & 45 & 19 & $64(36.0)$ & \multirow[t]{2}{*}{0.703} \\
\hline Female & 77 & 37 & $114(64.0)$ & \\
\hline \multicolumn{5}{|l|}{ Body mass index $\left(\mathrm{kg} / \mathrm{m}^{2}\right)$} \\
\hline Mean & 25.3 (SD 3.7) & 25.6 (SD 3.8) & & \multirow[t]{2}{*}{0.618} \\
\hline No. of patients $<23$ & 28 & 17 & $45(25.3)$ & \\
\hline 23-24.9 (overweight) & 36 & 11 & $47(26.4)$ & \multirow[t]{2}{*}{0.317} \\
\hline$\geq 25$ (obesity) & 58 & 28 & $86(48.3)$ & \\
\hline \multicolumn{5}{|l|}{ Smoking status } \\
\hline Non smoker & 101 & 43 & $144(80.9)$ & \multirow[t]{3}{*}{0.296} \\
\hline Ex-smoker & 19 & 13 & $32(1.1)$ & \\
\hline Current smoker & 2 & 0 & $2(18.0)$ & \\
\hline \multicolumn{5}{|l|}{ Presence of diabetes } \\
\hline Yes & 38 & 17 & $55(30.9)$ & \multirow[t]{2}{*}{0.916} \\
\hline No & 84 & 39 & $123(69.1)$ & \\
\hline \multicolumn{5}{|l|}{ History of cardiovascular disease } \\
\hline Yes & 8 & 5 & $13(7.3)$ & \multirow[t]{2}{*}{0.757} \\
\hline No & 114 & 51 & $165(92.7)$ & \\
\hline \multicolumn{5}{|l|}{ No. of anti-hypertensives taken } \\
\hline Monotherapy & 66 & 31 & $97(54.5)$ & \\
\hline Two drugs & 33 & 16 & $49(27.5)$ & \multirow[t]{2}{*}{0.866} \\
\hline Three or more drugs & 23 & 9 & $32(18.0)$ & \\
\hline \multicolumn{5}{|l|}{ Types of anti-hypertensives taken } \\
\hline Alpha-blockers & 9 & 7 & $16(9.0)$ & 0.267 \\
\hline Angiotensin-converting enzyme inhibitors & 34 & 15 & $49(27.5)$ & 0.881 \\
\hline Angiotensin receptor blockers & 17 & 9 & $26(14.6)$ & 0.820 \\
\hline Beta-adrenergic blockers & 28 & 10 & $38(21.3)$ & 0.555 \\
\hline Calcium channel blockers & 94 & 38 & $132(74.2)$ & 0.193 \\
\hline Diuretics & 10 & 5 & $15(8.4)$ & 1 \\
\hline Hydralazine & 8 & 5 & $14(7.9)$ & 0.757 \\
\hline Methyldopa & 7 & 2 & $9(5.1)$ & 0.722 \\
\hline
\end{tabular}


Table 2 BP responses to the deep breathing test in all patients $(N=178)$

\begin{tabular}{llll}
\hline Variables & Mean BP before DBT $(\mathrm{mmHg})$ & Mean BP after DBT $(\mathrm{mmHg})$ & $p$ value \\
\hline Systolic BP & 153.6 (SD 17.4) & $138.7($ SD 16.9) & $<0.001$ \\
Diastolic BP & 77.1 (SD 10.5) & 72.8 (SD 10.7) & $<0.001$
\end{tabular}

$B P$ blood pressure, $D B T$ deep breathing test

of the subjects was 65.0 and more were female patients (64\%). More than half of the subjects (54.5\%) were receiving monotherapy. Calcium channel blockers were the commonest (74.2\%) class of antihypertensives being used by the patients, followed by angiotensin-converting enzyme inhibitors (27.5\%), beta-adrenergic blockers (21.3\%), angiotensin receptor blockers (14.6\%), alpha-blockers (9.0\%), diuretics (8.4\%), hydralazine (7.9\%) and methyldopa (5.1\%). Other clinical characteristics of the subjects were summarized in Table 1. The baseline characteristics including age, sex, body mass index, smoking status, presence of diabetes and cardiovascular disease showed no statistically significant difference between the white-coat and non white-coat groups.

\section{Deep breathing test results}

In all subjects, the DBT reduced SBP by a mean of 14.9 $\mathrm{mmHg}$ and DBP by a mean of $4.3 \mathrm{mmHg}(p<0.001)$ (Table 2). 68.5\% (122 out of 178) of the subjects were found to have white-coat effect by ABPM. The mean SBP and DBP drop after the DBT for the white-coat effect group were $15.5 \mathrm{mmHg}$ and $4.4 \mathrm{mmHg}$ respectively while for the non white-coat effect group were $13.3 \mathrm{mmHg}$ and $3.8 \mathrm{mmHg}$ respectively.. Neither the SBP nor DBP drop showed a statistically significant difference. The areas under the ROC curve for SBP and DBP changes in all patients were $0.52(95 \%$ CI $0.43-0.61$, $p=0.611)$ and 0.53 (95\% CI $0.44-0.62, p=0.552)$ respectively, showing that they were uninformative (Table 3).

\section{Subgroup analysis with different pre-test SBP cut off}

In the sub-analysis of patients with different clinic pre-test SBP cut-off, the mean SBP drop showed significant difference in patients with clinic SBP $\geq 145$ $\mathrm{mmHg}$ before the DBT $(p=0.042)$. The ROC curve for both SBP and DBP change did not yield any significant results. However, the discriminating power of the DBT by using SBP change was improved with higher pre-test SBP cut-off, with an area under ROC curve of 0.68 (95\% CI $0.51-0.84$ ) and $p$ value reaching 0.07 when patients with $\mathrm{SBP}<165 \mathrm{mmHg}$ excluded (Table 4).

\section{Subgroup analysis with patients on beta-adrenergic blockers excluded}

$23 \%$ of the patients with white-coat effect and $17.9 \%$ of the non white-coat effect group were taking beta-adrenergic blockers. The difference in mean SBP and DBP drop after the DBT between the white-coat and non white-coat groups in patients not on beta-adrenergic blockers was not statistically significant. However, when combining the two variables, with different pre-test SBP cut-off and the exclusion of patients taking beta-adrenergic blockers, the difference in mean SBP drop reached statistical significance in patients with SBP $\geq 145 \mathrm{mmHg} \quad(p=0.043)$ and $\geq 165$ $\mathrm{mmHg}(p=0.035)$. (Table 5) On the other hand, the mean DBP drop did not show any statistically significant difference between the two groups by all means of the aforementioned analysis. Further analysis by means of the ROC curve (Table 5) showed that SBP change was a good diagnostic test for white-coat effect in patients with pre-test SBP $\geq 165 \mathrm{mmHg}$ with an area under curve of 0.72 (95\% CI 0.53-0.91, $\mathrm{p}=0.04$ ) (Fig. 1).

The corresponding sensitivity, specificity, positive and negative predictive values for SBP drop in patients not on beta-adrenergic blockers and with pre-test $\mathrm{SBP} \geq 165$ $\mathrm{mmHg}$ were shown in Table 6 . A drop of more than 10 $\mathrm{mmHg}$ in the SBP was highly sensitive (90.9\%), however, the specificity was only $36.4 \%$. If SBP drop was 30

Table 3 Deep breathing test results in all patients $(N=178)$

\begin{tabular}{|c|c|c|c|}
\hline \multirow[t]{2}{*}{ BP response to the deep breathing test } & \multicolumn{2}{|l|}{ White-coat effect } & \multirow[t]{2}{*}{$p$ value } \\
\hline & Present $(n=122)$ & Absent $(n=56)$ & \\
\hline Mean SBP drop (mmHg) & 15.5 (SD 12.0) & 13.3 (SD 11.7) & 0.247 \\
\hline Mean DBP drop (mmHg) & 4.4 (SD 5.2) & 3.8 (SD 4.3) & 0.436 \\
\hline Deep breathing test operating characteristics & Area under ROC curve & 95\% confidence interval (Cl) & $p$ value \\
\hline SBP change & 0.52 & $0.43-0.61$ & 0.611 \\
\hline DBP change & 0.53 & $0.44-0.62$ & 0.552 \\
\hline
\end{tabular}

$B P$ blood pressure, $S B P$ systolic blood pressure, $D B P$ diastolic blood pressure, $D B T$ deep breathing test, $R O C$ Receiver operating characteristic 
Table 4 Sub-group analysis of deep breathing test results with different pre-test SBP cut-off

\begin{tabular}{|c|c|c|c|}
\hline \multirow[t]{2}{*}{ BP response to the deep breathing test } & \multicolumn{2}{|l|}{ White-coat effect } & \multirow[t]{2}{*}{$p$ value } \\
\hline & Present & Absent & \\
\hline (i) $\mathrm{SBP} \geq 145 \mathrm{mmHg}(\mathrm{N}=118)$ & $n=78$ & $n=40$ & \\
\hline Mean SBP drop (mmHg) & 19.2 (SD 12.8) & $14.1(\mathrm{SD} 12.5)$ & *0.042 \\
\hline Mean DBP drop (mmHg) & 4.9 (SD 5.4) & 3.8 (SD 4.3) & 0.268 \\
\hline (ii) $\mathrm{SBP} \geq 155 \mathrm{mmHg}(\mathrm{N}=74)$ & $n=51$ & $n=23$ & \\
\hline Mean SBP drop (mmHg) & 20.8 (SD 14.5) & 15.1 (SD 13.0) & 0.107 \\
\hline Mean DBP drop (mmHg) & 4.8 (SD 6.3) & 4.3 (SD 4.2) & 0.739 \\
\hline (iii) $\mathrm{SBP} \geq 165 \mathrm{mmHg}(\mathrm{N}=43)$ & $n=30$ & $n=13$ & \\
\hline Mean SBP drop (mmHg) & 24.4 (SD 15.4) & 15.3 (SD 13.2) & 0.073 \\
\hline Mean DBP drop (mmHg) & 4.9 (SD 5.8) & 3.5 (SD 3.5) & 0.451 \\
\hline Deep breathing test operating characteristics & Area under ROC curve & 95\% confidence interval $(\mathrm{Cl})$ & $p$ value \\
\hline \multicolumn{4}{|l|}{ (i) $\mathrm{SBP} \geq 145 \mathrm{mmHg}(\mathrm{N}=118)$} \\
\hline SBP change & 0.60 & $0.49-0.70$ & 0.087 \\
\hline DBP change & 0.55 & $0.44-0.66$ & 0.365 \\
\hline \multicolumn{4}{|l|}{ (ii) $\mathrm{SBP} \geq 155 \mathrm{mmHg}(\mathrm{N}=74)$} \\
\hline SBP change & 0.61 & $0.48-0.74$ & 0.130 \\
\hline DBP change & 0.51 & $0.37-0.65$ & 0.912 \\
\hline \multicolumn{4}{|l|}{ (iii) $\mathrm{SBP} \geq 165 \mathrm{mmHg}(\mathrm{N}=43)$} \\
\hline SBP change & 0.68 & $0.51-0.84$ & 0.070 \\
\hline DBP change & 0.57 & $0.39-0.74$ & 0.500 \\
\hline
\end{tabular}

$B P$ blood pressure, $S B P$ systolic blood pressure, $D B P$ diastolic blood pressure, $D B T$ deep breathing test, $R O C$ receiver operating characteristic

mmHg or more, sensitivity decreased to $40.9 \%$ but specificity increased to $90.9 \%$. The positive predictive value (PPV), ranging from 74 to $90 \%$, was most predictive when the SBP drop was more than $30 \mathrm{mmHg}$. The negative predictive value (NPV) was less informative, with the highest value reaching $67 \%$ if SBP drop was more than $10 \mathrm{mmHg}$.

\section{Discussion}

Even though ABPM remains the gold standard in the diagnosis of white-coat effect in hypertension, it requires specific equipment and extra manpower that might not be readily available in every primary care physician's office. A much simpler DBT would be invaluable to detect white-coat effect and avoid unnecessary over-treatment.

Our study showed an important finding that DBT was useful in detecting white-coat effect in a specific group of Chinese hypertensive patients i.e. patients with pre-test SBP $\geq 165 \mathrm{mmHg}$ and who were not taking beta-adrenergic blockers. In this group of patients, the DBT showed high specificity (90.9\%) if the post-test SBP drop was more than $30 \mathrm{mmHg}$. The relatively high PPV and low NPV implied that DBT was most useful to rule in the existence of white-coat effect.
Our study was one of the studies with larger sample size as compared to previous studies and probably the first to examine the deep breathing test's applicability in Chinese patients. Furthermore, our study was the first to have taken into consideration the practicality of performing the DBT in actual clinical setting where the patients were more likely to be continued on their usual drug regime while performing the DBT. Neither the previous studies conducted by Federico et al. and Marion et al. took into account for the types of anti-hypertensives the patients were taking while they were performing the DBT, while in the Jose et al. study, the study subjects had anti-hypertensive withdrawn for 2-3 weeks before attempting the DBT, which might be less practical in a non-research setting.

Our study added information that beta-adrenergic blockers and different clinic SBP cut-off would affect the DBT performance. Since higher office SBP was positively correlated with white-coat effect, we postulated that patients with higher pre-test SBP would exhibit significant difference in BP responses after DBT between the white-coat and non white-coat groups. Though the mean SBP drop between the two groups did not show increasing significance as we moved towards higher SBP cut-off, it reached statistical significance across both groups with SBP $\geq 145 \mathrm{mmHg}$ and $\geq 165 \mathrm{mmHg}$ and 
Table 5 Sub-analysis of deep breathing test results with exclusion of patients on beta-adrenergicblockers

\begin{tabular}{|c|c|c|c|}
\hline \multirow[t]{2}{*}{$\mathrm{BP}$ response to the deep breathing test } & \multicolumn{2}{|l|}{ White-coat effect } & \multirow[t]{2}{*}{$p$ value } \\
\hline & Present & Absent & \\
\hline A. Patients not on beta-adrenergic blockers $(N=140)$ & $n=94$ & $n=46$ & \\
\hline Mean SBP drop (mmHg) & 15.7 (SD 11.5) & $12.8(S D$ 11.0) & 0.149 \\
\hline Mean DBP drop (mmHg) & $4.5(\mathrm{SD} 5.1)$ & 3.9 (SD 4.3) & 0.465 \\
\hline \multicolumn{4}{|c|}{ B. Patients not on beta-adrenergic blockers and with different clinic SBP cut-off before DBT } \\
\hline (i) $\mathrm{SBP} \geq 145 \mathrm{mmHg}(\mathrm{N}=92)$ & $n=58$ & $n=34$ & \\
\hline Mean SBP drop (mmHg) & 19.8 (SD 12.1) & $14.5(\mathrm{SD} 11.5)$ & *0.043 \\
\hline Mean DBP drop (mmHg) & 4.9 (SD 5.2) & 4.1 (SD 4.3) & 0.449 \\
\hline (ii) $\mathrm{SBP} \geq 155 \mathrm{mmHg}(\mathrm{N}=58)$ & $n=38$ & $n=20$ & \\
\hline Mean SBP drop (mmHg) & $22.0(S D 13.4)$ & 15.1 (SD 13.7) & 0.068 \\
\hline Mean DBP drop (mmHg) & 4.9 (SD 6.0) & 4.6 (SD 4.4) & 0.847 \\
\hline (iii) $\mathrm{SBP} \geq 165 \mathrm{mmHg}(\mathrm{N}=33)$ & $n=22$ & $\mathrm{n}=11$ & \\
\hline Mean SBP drop (mmHg) & $25.6(S D$ 13.1) & 14.6 (SD 14.3) & ${ }^{*} 0.035$ \\
\hline Mean DBP drop (mmHg) & 6.1 (SD 5.6) & 3.8 (SD 3.6) & 0.232 \\
\hline Deep breathing test operating characteristics & Area under ROC curve & 95\% confidence interval $(\mathrm{Cl})$ & p value \\
\hline \multicolumn{4}{|l|}{ A. Patients not on beta-adrenergic blockers $(N=140)$} \\
\hline SBP change & 0.56 & $0.46-0.66$ & 0.288 \\
\hline DBP change & 0.53 & $0.43-0.63$ & 0.554 \\
\hline \multicolumn{4}{|c|}{ B. Patients not on beta-adrenergic blockers and with different clinic SBP cut-off before DBT } \\
\hline \multicolumn{4}{|l|}{ (i) $\mathrm{SBP} \geq 145 \mathrm{mmHg}(\mathrm{N}=92)$} \\
\hline SBP change & 0.62 & $0.50-0.73$ & 0.066 \\
\hline DBP change & 0.54 & $0.41-0.66$ & 0.580 \\
\hline \multicolumn{4}{|l|}{ (ii) $\mathrm{SBP} \geq 155 \mathrm{mmHg}(\mathrm{N}=58)$} \\
\hline SBP change & 0.64 & $0.49-0.78$ & 0.094 \\
\hline DBP change & 0.51 & $0.35-0.66$ & 0.948 \\
\hline \multicolumn{4}{|l|}{ (iii) $\mathrm{SBP} \geq 165 \mathrm{mmHg}(\mathrm{N}=33)$} \\
\hline SBP change & 0.72 & $0.53-0.91$ & *0.040 \\
\hline DBP change & 0.62 & $0.42-0.82$ & 0.260 \\
\hline
\end{tabular}

$B P$ blood pressure, $S B P$ systolic blood pressure, $D B P$ diastolic blood pressure, $D B T$ deep breathing test, $R O C$ receiver operating characteristic

patients not on beta-adrenergic blockers. The findings also supported the evidence that beta-adrenergic blockers could modify the baroreflex and hence affect the DBT results.

Previous studies showed conflicting evidence on whether the drop of SBP or DBP post-DBT could be used to evaluate the presence of white-coat effect [29-32]. Our study showed that DBP drop was not useful in detecting white coat effect which was compatible with most of the other published studies [29-31]. .For SBP drop, our study did not reach a significant value when all patient analysis was performed. Ethnicity might have partly accounted for this difference. Another reason we postulated was the way that DBT was performed, which differed among studies. In the Marion et al. study, the study subjects were asked to perform 3 or 4 cycles of deep breathing in $30 \mathrm{~s}$ while in the Federico et al. study, the number of deep breathing cycles was not specified. Only in the Jose et al. study were the patients asked to perform DBT according to the analog clock who simulated $0.1 \mathrm{~Hz}$ breathing cycle. The advantage of which was a more consistent and reproducible test result and also more conforming to the original idea behind synchronising the breathing cycle with the innate cardiovascular rhythms to modulate the baroreflex.

\section{Limitation}

Our study showed a significant result after exclusion of patients on beta-adrenergic blockers and those with pre-test SBP $<165 \mathrm{mmHg}$. However, the sample size by such exclusivity became smaller and hence affected the statistical accuracy to find a precise SBP cut-off for distinguishing between the white-coat and 


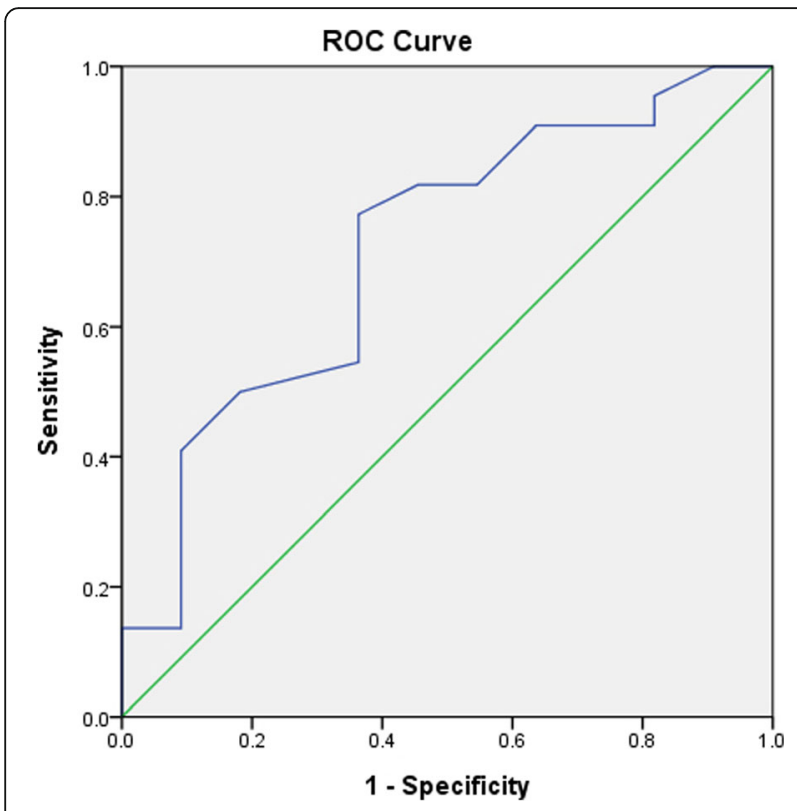

Fig. 1 ROC curve in patients with $S B P \geq 165 \mathrm{mmHg}$ showed that SBP change was a good diagnostic test for white-coat effect with the area under curve 0.72 ( $95 \% \mathrm{Cl} 0.53-0.91, p=0.04)$

non white-coat effect. Further research is suggested to specifically investigate this sub-group with a larger sample size. Moreover, the study was conducted in only one single clinic which was specialized on assessing hypertensive patients with suspected white-coat effect. The clinic had exceptionally more patients with white-coat effect diagnosed (68.5\%) and the results might not be able to be generalised to all primary care clinic settings in Hong Kong.

Throughout the study, there were several occasions where the post DBT blood pressures were higher than the pre-test values. As mentioned earlier, the device guided breathing cycle had its advantages, nonetheless, it also increased the anxiety in some of our patients during the attempt to synchronise their breathing rate to that of the counter on the mobile device. More training and attempts might be needed to allow the patients more adapt to the deep breathing exercise and produce a more pronounced blood pressure lowering effect. For those patients who

Table 6 Deep breathing test operating characteristics for SBP drop in patients not on beta-adrenergic blockers and with pretest SBP $\geq 165 \mathrm{mmHg}$

\begin{tabular}{lllll}
\hline Cut-off value & Sensitivity (\%) & Specificity (\%) & PPV (\%) & NPV (\%) \\
\hline$>10 \mathrm{mmHg}$ & 90.9 & 36.4 & 74 & 67 \\
$>20 \mathrm{mmHg}$ & 77.3 & 63.6 & 81 & 58 \\
$>30 \mathrm{mmHg}$ & 40.9 & 90.9 & 90 & 43 \\
$>40 \mathrm{mmHg}$ & 13.6 & 90.9 & 75 & 34
\end{tabular}

$S B P$ systolic blood pressure, $P P V$ positive predictive value, NPV negative predictive value showed a paradoxically increase in blood pressure after DBT, further evaluation with a standard ABPM should be performed.

\section{Conclusion}

The DBT could not be clinically applied to all Chinese patients with suspected white-coat effect. However, the study proved that it would be a potential screening and diagnostic test for white-coat effect under certain selection criteria; i.e. in patients with a pre-test SBP of $\geq 165$ $\mathrm{mmHg}$ and who were not taking beta-adrenergic blockers. Future larger scale studies should be conducted to enhance the statistical accuracy and generalisability of the results.

\section{Abbreviations}

ABPM: Ambulatory blood pressure monitoring; BP: Blood pressure; Cl: Confidence interval; DBP: Diastolic blood pressure; DBT: Deep breathing test; NPV: Negative predictive value; PPV: Positive predictive value; ROC: Receiver operating characteristic; SBP: Systolic blood pressure

\section{Acknowledgements}

We would like to thank all nurses and doctors involved in the collection of the trial data.

\section{Funding}

No funding was received since the trial was conducted under routine clinic circumstances.

\section{Availability of data and materials}

The datasets used and/or analysed during the current study are available from the corresponding author on reasonable request.

\section{Authors' contributions}

Dr. KSC was the main party overlooking the running of the trial and acquisition of data, drafting and writing of the manuscript. Dr. KPLL and Dr. PFC were the supervisors of the trial, and were involved in the conception and design of the trial and also revising the manuscript. Dr. MHML was responsible in the data analysis of trial. Dr. VKDC was involved in the revision of the manuscript. All authors read and approved the final manuscript.

\section{Ethics approval and consent to participate}

This study was approved by Kowloon East Cluster/ Kowloon Central Cluster Research Ethics Committee/Institutional Review Board of Hospital Authority of Hong Kong under the registration KC/KE-16-0084/ER-3. All study subjects gave written consent before recruitment. There was no reported adverse event from trial.

\section{Consent for publication}

Not applicable.

\section{Competing interests}

The authors declare that they have no competing interests.

\section{Publisher's Note}

Springer Nature remains neutral with regard to jurisdictional claims in published maps and institutional affiliations.

Received: 1 October 2018 Accepted: 19 December 2018

Published online: 01 February 2019

\section{References}

1. Lim SS, Vos T, Flaxman AD, Danaei G, Shibuya K, et al. A comparative risk assessment of burden of disease and injury attributable to 67 risk factors and risk factor clusters in 21 regions, 1990-2010: a systematic analysis for the Global Burden of Disease Study 2010. Lancet. 2012;380:2224-60. 
2. Leung G, Ni M, Wong P, Lee P, Chan B, Stewart S, et al. Cohort profile: FAMILY cohort. Int J Epidemiol. 2015;46(2):e1.

3. Collins R, Peto R, MacMahon S, et al. Blood pressure, stroke, and coronary heart disease. Part 2, short-term reductions in blood pressure: overview of randomised drug trials in their epidemiological context. Lancet. 1990;335: 827-38.

4. The Hypertension Detection and Follow-up Program Cooperative Group Division of heart and vascular diseases, National Heart, Lung, and Blood Institute, National Institutes of Health, Bethesda, Md. Five-year findings of the hypertension detection and follow-up program: I. reduction in mortality of persons with high blood pressure, including mild hypertension. JAMA. 1979;242(23):2562.

5. Falaschetti E, Chaudhury M, Mindell J, Poulter N. Continued improvement in hypertension management in England: results from the Health Survey for England 2006. Hypertension. 2009;53(3):480.

6. Hajjar I, Kotchen TA. Trends in prevalence, awareness, treatment, and control of hypertension in the United States, 1988-2000. JAMA. 2003;290: 199-206.

7. Lloyd-Jones DM, Evans JC, Larson MG, O'Donnell CJ, Rocella EJ, Levy D. Differential control of systolic and diastolic blood pressure: factors associated with lack of blood pressure control in the community. Hypertension. 2000;36:594-9.

8. Bunker J, Callister W, Chang C, Sever P. How common is true resistant hypertension? J Hum Hypertens. 2010;25(2):137-40.

9. National Institute of Health and Clinical Excellence. Hypertension: clinical management of primary hypertension in adults. London: NICE; 2011. NICE clinical guideline 127

10. O'Brien E, Coats A, Owens P, Petrie J, Padfield PL, Littler WA, de Swiet M, Mee F. Use and interpretation of ambulatory blood pressure monitoring: recommendations of the British hypertension society. BMJ. 2000;320:1128-34.

11. Streitel KL, Graham JE, Pickering TG, Gerin W. Explaining gender differences in the white coat effect. Blood Press Monit. 2011;16:1-6.

12. MacDonald MB, Laing GP, Wilson MP, Wilson TW. Prevalence and predictors of white-coat response in patients with treated hypertension. CMAJ. 1999; 161:265-9.

13. de la Sierra A, Segura J, Banegas J, Gorostidi M, de la Cruz J, Armario P, et al. Clinical features of 8295 patients with resistant hypertension classified on the basis of ambulatory blood pressure monitoring. Hypertension. 2011: 57(5):898-902.

14. Brown M, Buddle M. Martin a. is resistant hypertension really resistant? Am J Hypertens. 2001;14(12):1263.

15. Myers MG. The white coat effect in treated hypertension. Blood Press Monit. 1996;: :247-9.

16. Little P, Barnett J, Barnsley L, Marjoram J, Fitzgerald Berron A, Mant D. Comparison of agreement between different measures of blood pressure in primary care and daytime ambulatory blood pressure. BMJ. 2002;325:254-9.

17. Myers MG, Reeves RA. White coat phenomenon in patients receiving antihypertensive therapy. Am J Hypertens. 1991;4:844-9.

18. Liana FL, Mateus DS, Priscila SL, et al. White coat effect and masked uncontrolled hypertension in treated hypertensive-diabetic patients: prevalence and target organ damage. J Diabetes. 2015;7(5):699-707.

19. Pierdomenico SD, Mezzetti A, Lapenna D, Guglielmi MD, Mancini M, Salvatore L, et al. 'White-coat' hypertension in patients with newly diagnosed hypertension: evaluation of prevalence by ambulatory monitoring and impact on cost of health care. Eur Heart J. 1995;16:692-7.

20. Huang CC, Wu TC, Lin SJ, Chen JW, Leu HB. Clinical predictors of significant white-coat effect in non-diabetic hypertensive patients. Acta Cardiol Sin. 2010;26:151-6.

21. Manios E, Koroboki E, Tsivgoulis G, Spengos K, Spiliopoulou I, Brodie F, et al. Factors influencing White-coat effect. Am J Hypertens. 2008;21(2):153-8.

22. Redon J, Campos C, Narciso ML, Rodicio JL, Pascual JM, Ruilope LM. Prognostic value of ambulatory blood pressure monitoring in refractory hypertension: a prospective study. Hypertension. 1998;31(2):712-8.

23. White WB. Ambulatory blood pressure as a predictor of target organ disease and outcome in the hypertensive patient. Blood Press Monit. 1999; 4(3-4):181-4.

24. Parati G, Ulian L, Santucciu C, Omboni S, Mancia G. Difference between clinic and daytime blood pressure is not a measure of the white-coat effect. Hypertension. 1998;31:1185-9.

25. Mancia G, Fagard R, Narkiewicz K, et al. 2013 ESH/ESC guidelines for the management of arterial hypertension: the Task Force for the Management of
Arterial Hypertension of the European Society of Hypertension (ESH) and of the European Society of Cardiology (ESC). Eur Heart J. 2013:34(28):2159-219.

26. Staessen JA, Asmar R, De Buyzere M, Imai Y, Parati G, Shimada K, Stergiou G, Redón J, Verdecchia P. Participants of the 2001 consensus conference on ambulatory blood pressure monitoring. Task force II: blood pressure measurement and cardiovascular outcome. Blood Press Monit. 2001;6:355-70.

27. Mori H, Yamamoto H, Kuwashima M, Saito S, Ukai H, Hirao K, et al. How does deep breathing affect office blood pressure and pulse rate? Hypertens Res. 2005;28:499-504.

28. Bernardi L, Porta C, Spicuzza L, Bellwon J, Spadacini G, Frey AW, et al. Slow breathing increases arterial baroreflex sensitivity in patients with chronic heart failure. Circulation. 2002;105:143-5.

29. Augustovski FA, Calvo CB, Deprati M, Waisman G. The deep-breath test as a diagnostic maneuver for white-coat effect in hypertensive patients. J Am Board Fam Pract. 2004;17:184-9.

30. Tomičić M, Petric D, Rumboldt M, Carević V, Rumboldt Z. Deep breathing: a simple test for white coat effect detection in primary care. Blood Press. 2015;24(3):158-63.

31. Thalenberg JM, Povoa RM, Bombig MT, Sa GA, Atallah AN, Luna Filho B. Slow breathing test increases the suspicion of white-coat hypertension in the office. Arq Bras Cardiol. 2008;91:243-9.

32. Yoshihara K, Fukui T, Osawa H, Ishii Y, Morita H, Yamashiro S, et al. Deep breathing test (DBT) in predicting white coat hypertension. Fukuoka Igaku Zasshi. 1993:84:395-401.

33. Parati G, Mutti E, Frattola A, Castiglioni P, di Rienzo M, Mancia G. Betaadrenergic blocking treatment and 24-hour baroreflex sensitivity in essential hypertensive patients. Hypertension. 1994;23(6 Pt 2):992-6.

34. Niemelä M, Airaksinen $\mathrm{K}$, Huikuri H. Effect of Beta-blockade on heart rate variability in patients with coronary artery disease. J Am Coll Cardiol. 1994; 23(6):1370.

35. Hajian-Tilaki K. Sample size estimation in diagnostic test studies of biomedical informatics. J Biomed Info. 2014;48:193-204.

Ready to submit your research? Choose BMC and benefit from:

- fast, convenient online submission

- thorough peer review by experienced researchers in your field

- rapid publication on acceptance

- support for research data, including large and complex data types

- gold Open Access which fosters wider collaboration and increased citations

- maximum visibility for your research: over $100 \mathrm{M}$ website views per year

At $\mathrm{BMC}$, research is always in progress.

Learn more biomedcentral.com/submissions 